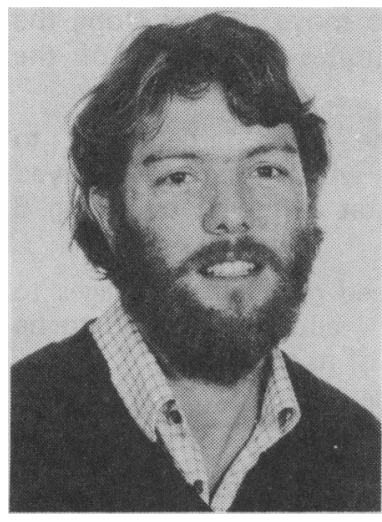

J. P. Nicholl

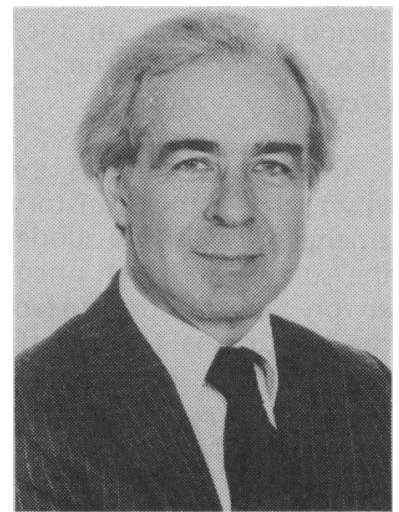

B. T. Williams

\title{
INJURIES SUSTAINED BY RUNNERS DURING A POPULAR MARATHON
}

\author{
J. P. NICHOLL, BA, MSc, Statistician and B. T. WILLIAMS, MD, FFCM, Senior Lecturer \\ Department of Community Medicine, University of Sheffield Medical School, \\ Beech Hill Road, Sheffield S10 2RX
}

Key Words: Sports injuries, Marathon, Casualties.

\section{INTRODUCTION}

Open-entry marathon running events are becoming increasingly common. In 1982 more than a hundred such events were planned in Britain (Running Magazine, 1982), and the popularity of these events may still be on the increase. The tens of thousands of runners taking part may be at some risk of sustaining injuries whilst training for and running in these races. Nicholl and Williams (1982a) have given some information about the numbers and types of injuries sustained in training by those entrants to the 1982 Sheffield Marathon who were prevented from racing by a training injury. Maughan and Miller (1982) have given complementary information about the numbers and types of injuries sustained in training by those who ran in the 1982 Aberdeen Marathon. Nicholl and Williams also described the after-effects for runners who completed the Sheffield Marathon, and in another paper (Nicholl and Williams, 1982b) have reported the number of requests for treatment at first-aid posts during the 1982 Sheffield Marathon and have described the injuries that were presented. These numbers can be used to forecast the workload of the first-aid services during a popular marathon. However, they cannot be used to assess the risk of sustaining injuries during the race because many runners presented more than once to the first-aid services, sometimes with the same problem and sometimes with a different one. Accordingly, in this paper we report the number and types of casualties which occurred during the 1982 Sheffield Marathon (which had a half-marathon option) and relate them to characteristics of the runners concerned so that the risk of sustaining particular injuries can be assessed.

\section{METHOD}

Twelve first-aid posts were spaced along the $\mathbf{2 6 . 2}$ mile route of the Sheffield Marathon. Each first-aid post was staffed by a number of Red Cross volunteers, physiotherapists and at least one trained nurse. There was one medical officer at the fourth post just before the half-way point; three at the half-marathon finish; none at the one after; but one each at all the following posts and five at the full-marathon finish. The "sweeper bus" contained one trained nurse and two Red Cross volunteers.

The race started at noon on 6th June, 1982 in an air temperature of $23.7^{\circ} \mathrm{C}$, relative humidity of $82 \%$ and wind speed of 5 knots. The race was run almost entirely on roads and pavements, and the route was unexceptional, being quite flat. Medical Student observers recorded the clinical details of any contact made by a runner with one of the first-aid posts, or with the firstaid services on board the "sweeper bus". Those abandoning the run for reasons other than injury or illness are not, of course, included in the analysis.

Data about the runners (age, sex, previous experience 


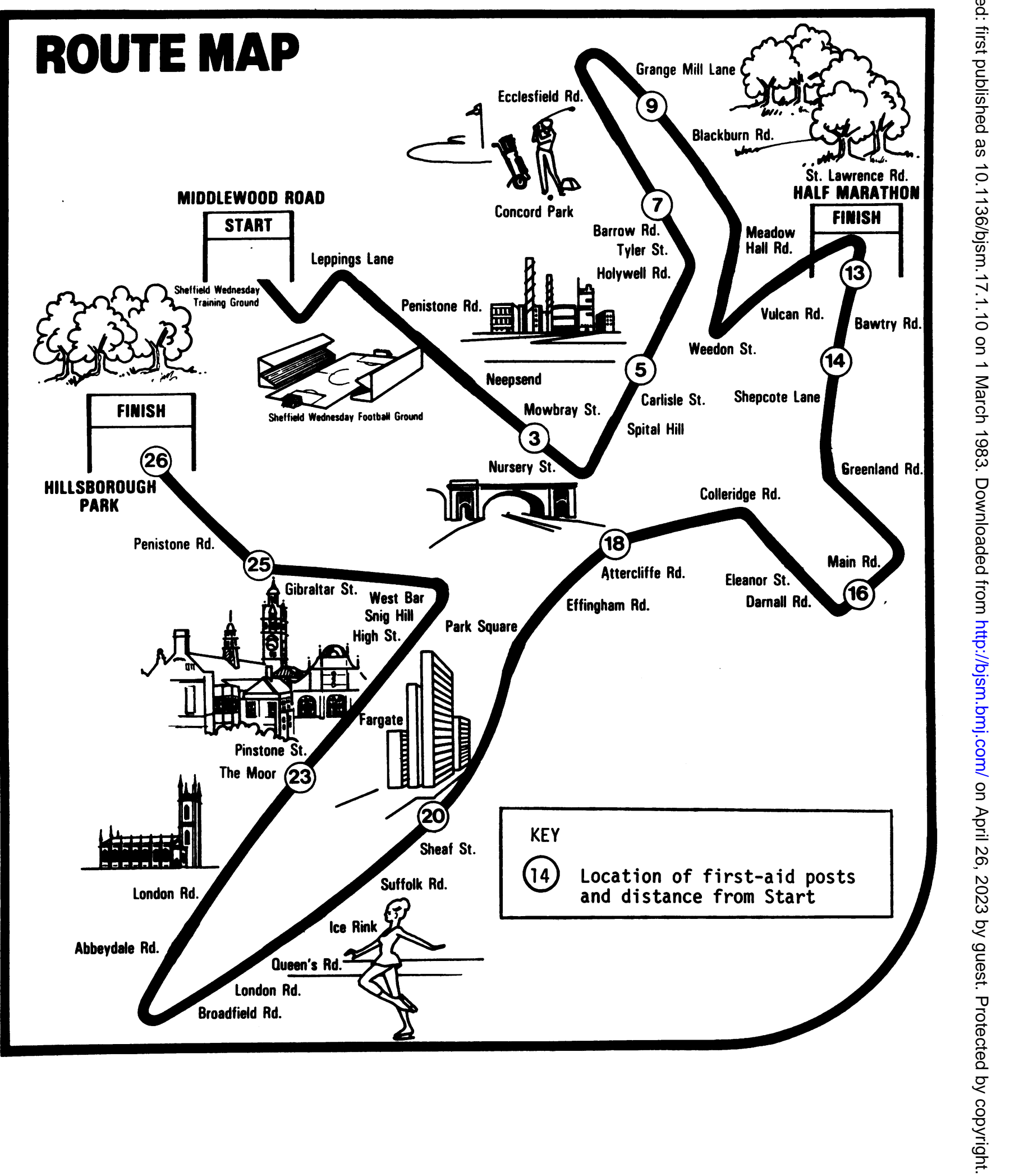


of running a half- or full-marathon, and intended distance on this occasion) were obtained from their entry forms and linked, where applicable, to the data recorded at the casualty stations.

\section{RESULTS}

Of the 3,462 runners $(3,264$ males, 198 females) who registered for the start of the race 2,602 had specified a full-marathon intention when they entered, but 500 (19\%) of these finished at the half-marathon stage and a further $122(5 \%)$ did not complete the course. A halfmarathon intention was given by 825 entrants (the intentions of the remaining 35 were unknown), but 38 (5\%) did not finish and $184(22 \%)$ went on to complete the full-marathon. All those who ran beyond the halfmarathon stage were classed as de facto full-marathon runners $(2,289)$, while all those who finished at the halfmarathon point or did not reach it, having said they intended to, were classed as half-marathon runners $(1,140)$. The full-marathon winner's time was 2 hours 29 minutes.

The half-marathon runners sustained few injuries; $41(4 \%)$ of them made a total of 46 contacts with firstaid stations, presenting $\mathbf{4 4}$ separate injuries (average $\mathbf{1 . 1}$ per contacting runner), and these are not considered further. The injury rate among full-marathon runners was much higher; $409(18 \%)$ runners made 580 contacts for 534 separate conditions. Only 53 females were full-marathon runners but 17 (32\%) made contact, compared with $931(17.5 \%)$ of the 2,236 males. (The sex of one contacting runner was not recorded). Significantly fewer older runners $(45 / 350$ aged 40 years or over $=13 \%)$ than younger ones $(119 / 737=16 \%$ aged $30-39 ; 228 / 1,202=19 \%$ aged $18-29)(p<0.05)$ made contact. (The age and previous experience of 17 contacting runners was not recorded). Those with previous experience of running either a full- or halfmarathon had a significantly lower contacting rate $(116 / 806=14 \%)$ than those without any $(276 / 1,483=$ $19 \%)(p<0.05)$ and this was true for each age group.

The faster runners were classified as those who completed the course in less than $3 \frac{1}{2}$ hours, or who were on schedule for finishing in less than $3 \frac{1}{2}$ hours when they first made contact with the first-aid services. The runners of "intermediate" speed were those who finished, or were on schedule to finish in over $3 \frac{1}{2}$ but under $4 \frac{1}{2}$ hours, and the rest were classified as "slow". For these groups the differences in the contact rates were significant at the $10 \%$ level. The faster runners had a lower contact rate $(53 / 370=14 \%)$ than the intermediate runners $(247 / 1,387=18 \%)$ who in turn had a lower contact rate than the slow runners $(103 / 510=20 \%)$.

Many of the runners who contacted the first-aid stations had more than one injury, some having as many as five. The average numbers of injuries per contacting

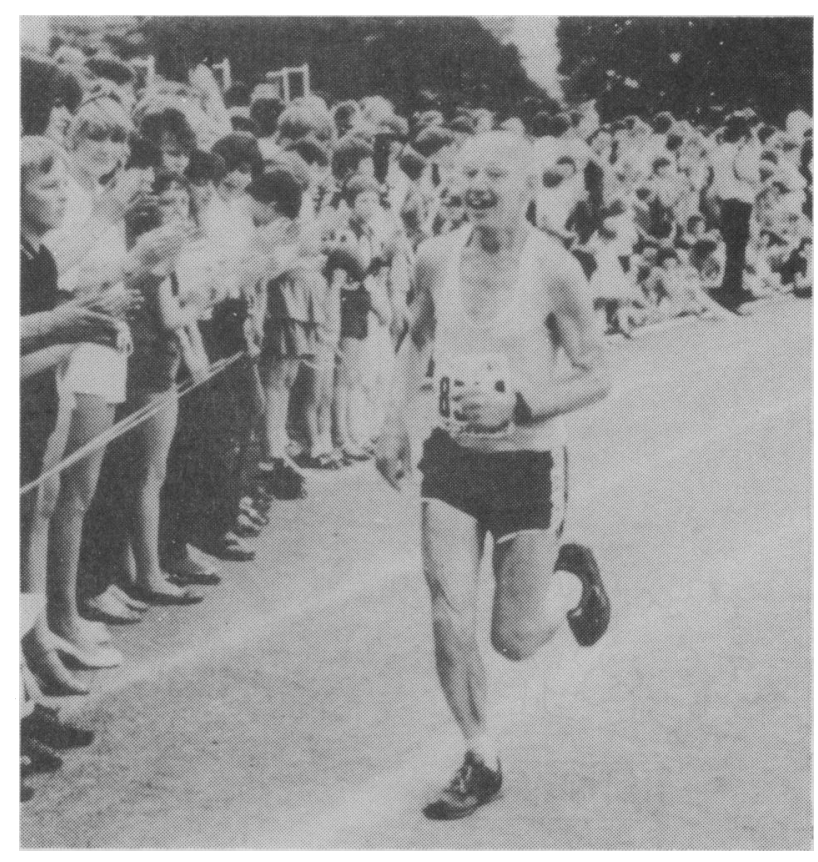

73 year old finishing the full marathon

runner were similar among the various age-groups and among the various levels of previous running experience. The faster runners had a higher average number of injuries (1.5) than those whose speed was slower at first contact (1.3), but the difference is not statistically significant.

Amongst the 534 separate conditions presented by the de facto full-marathon runners the most common localised injuries were muscle or joint conditions of the lower limbs $(50 \%)$, particularly stiffness, cramp, torn musculature or ligaments (Table 1). Next commonest were topical skin conditions $(17 \%)$, predominantly foot blisters or flexural chafing and just three cases, all among males, of sore or bleeding nipples. Constitutional disturbances which are potentially serious (extreme thirst; severe exhaustion with or without confusion; peripheral circulatory collapse; alimentary disturbances such as vomiting, diarrhoea; syncope) accounted for $28 \%$ of all the injuries that were presented. However, the proportions of "injuries" which were constitutional were much higher amongst those who had run fullmarathons previously $(48 \%)$ and amongst those who were running comparatively fast up to the point of first contact (47\%).

Speed and previous experience are no doubt associated with one another. Amongst runners making contact who had not reported any previous experience of running the full-marathon the proportions of conditions presented which were constitutional were similar 
TABLE I

Distribution of types of injury presented by full-marathon runners. Percentages of $\mathbf{5 3 4}$ separate injuries.

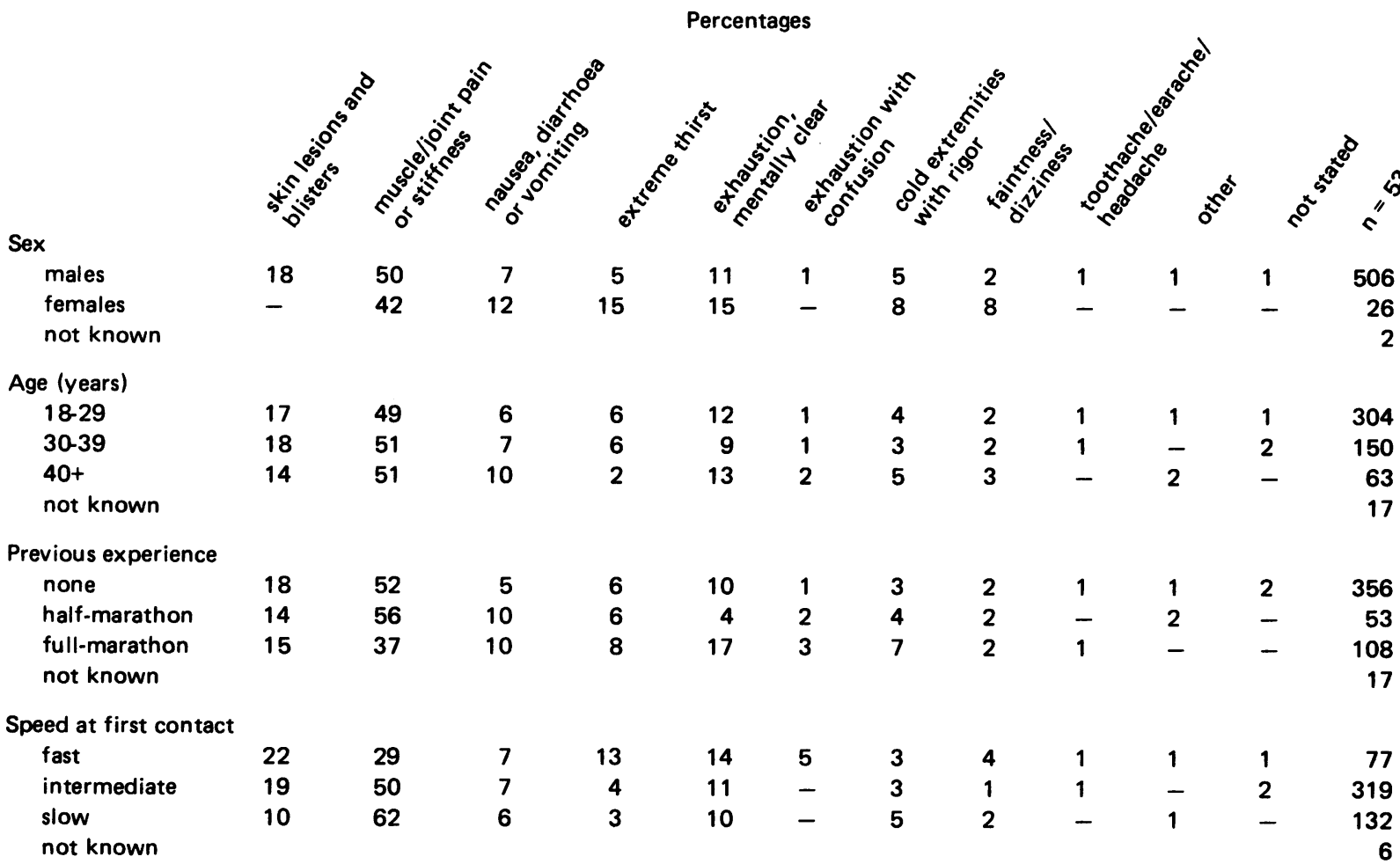

* Percentages in the rows may not sum exactly to $100 \%$ because of rounding-up

\section{TABLE II}

Percentages of injuries which were constitutional disturbances according to runners' previous experience and speed at first contact.

\begin{tabular}{|c|c|c|c|}
\hline & \multicolumn{3}{|c|}{ presenting injuries } \\
\hline & $\begin{array}{l}\text { speed at } \\
\text { first contact }\end{array}$ & number & $\begin{array}{l}\% \text { constitutional } \\
\text { disturbances }\end{array}$ \\
\hline \multirow{3}{*}{$\begin{array}{l}\text { Experience of full } \\
\text { marathon }\end{array}$} & fast & 42 & $62 \%$ \\
\hline & intermediate & 50 & $38 \%$ \\
\hline & slow & 14 & $43 \%$ \\
\hline \multirow{3}{*}{$\begin{array}{l}\text { No experience of } \\
\text { full marathon }\end{array}$} & fast & 32 & $28 \%$ \\
\hline & intermediate & 243 & $28 \%$ \\
\hline & slow & 108 & $24 \%$ \\
\hline
\end{tabular}

whatever their speed (Table II). But not only were the proportions of constitutional conditions higher for runners with previous experience at the full distance in each speed category, they also differed significantly among those runners at different speeds. More than $60 \%$

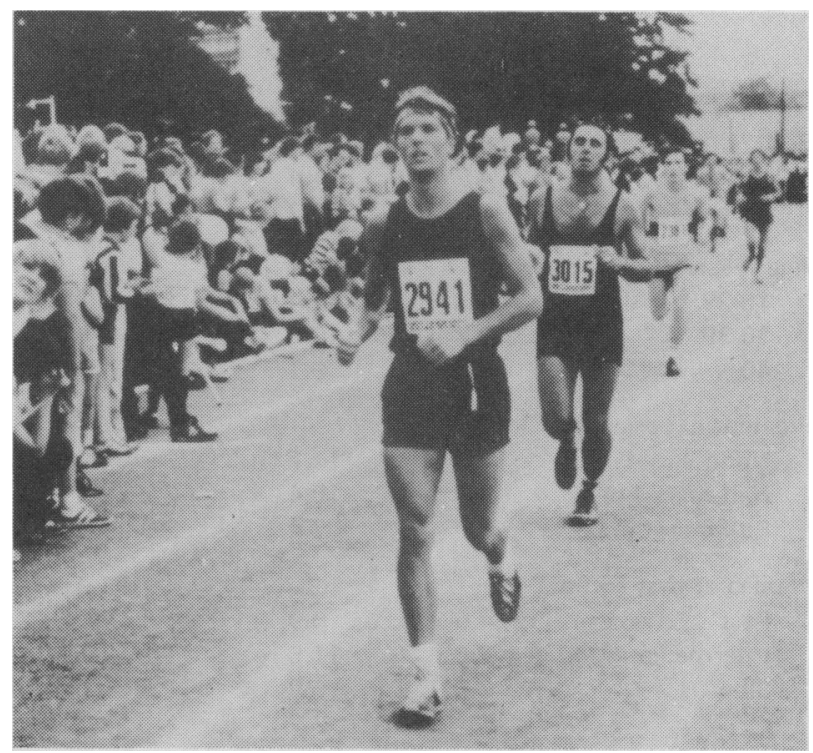

J. P. Nicholl, co-author, finishing 827th! 
of the conditions presented for treatment by faster runners with previous experience were constitutional compared with $40 \%$ for the slower runners. It is not clear why differences between faster and slower runners should be manifest only amongst those with previous experience.

The higher proportions of the potentially more serious conditions amongst contacting runners who had previous experience might be the result of either a higher rate of occurrence of constitutional injuries or a lower rate of occurrence of the minor localised injuries. In fact $6.5 \%$ of the de facto full-marathon runners who had previous experience presented with constitutional problems compared with only $4.3 \%$ without experience. This difference is however not significant leaving the issue in doubt. Similarly $6.2 \%$ of the faster runners presented with constitutional problems compared with $4.6 \%$ of the others. Once again it is not certain from these data whether the faster runners were more likely to develop the potentially more serious condition.

The percentages of the numbers of de facto fullmarathon runners who sustained injury by characteristics of the runners and the type of injury are given in Table III. These percentages represent the injury rates per 100 full-marathon runners and they provide estimates of the risk to different types of runners in a popular marathon of sustaining a particular type of injury. With the exception of muscle or joint problems the injury rates are in every case less than 10 in 100 and are usually less than 5 in $\mathbf{1 0 0}$. However the rates sometimes differ by a factor of two between runners with different characteristics.

Forty per cent of the injuries presented for first-aid for the first time at the full-marathon finishing point, and over half these were for constitutional upsets. It was at the eighth first-aid post, after $\mathbf{2 0}$ miles, that the number of presenting injuries increased dramatically, and thereafter constitutional problems became proportionately more significant.

Only 26 of the 2,289 full-marathon runners required transfer to hospital, 24 with constitutional problems and two with leg injuries. All but four were discharged the same evening.

\section{DISCUSSION}

The Sheffield Marathon was run in conditions of heat and humidity which were among the most taxing likely to occur in Britain. Three quarters of the full-marathon

\section{TABLE III}

Percentages of full-marathon runners who sustained injuries by characteristic of the runners and type of injury.

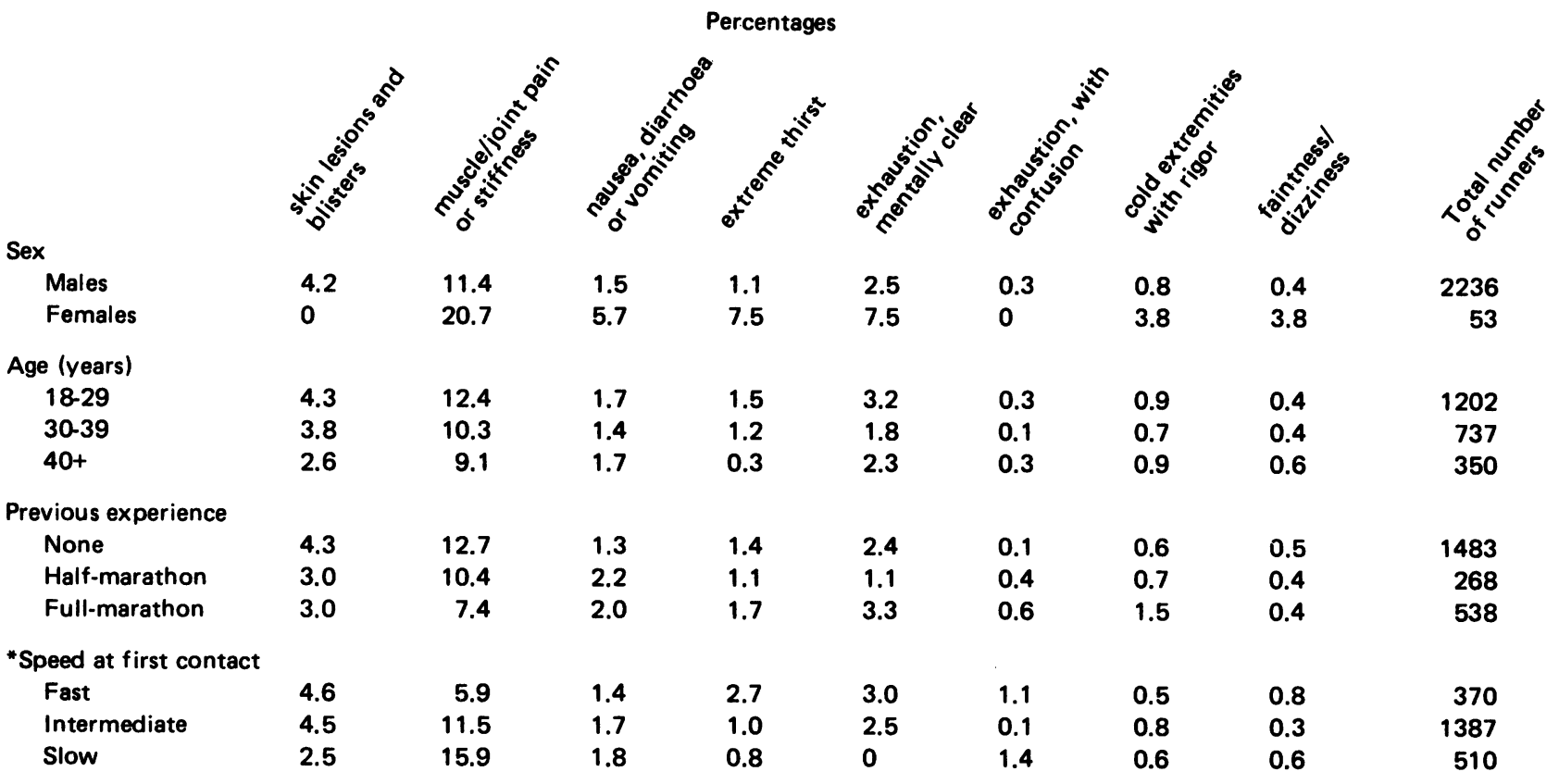

* The 2289 de facto full-marathon runners included 22 who ran beyond the half-marathon stage but neither finished nor contacted a first-aid post. Their speed cannot be classified and they are excluded from this part of the Table. 
runners had no previous experience of running the distance and $16 \%$ were over 40 years old. Yet only $5 \%$ of the runners made contact with the first-aid services as a result of any constitutional problem. Why were the numbers of those potentially more serious injuries smaller than had been anticipated?

One reason is simply that very little reliable information was available with which to make accurate forecasts. Secondly if, as suggested here, the occurrence of constitutional problems is related to the speed and effort of the runners, then the fact that the Sheffield Marathon was on the whole run slowly may have contributed to reducing the numbers developing such problems. Thirdly, and perhaps most importantly, there was a half-marathon option. One fifth of those who, on application, planned to run the full distance took this option. An officially-recognised and timed halfmarathon finishing point allows runners to stop early with a sense of accomplishment before getting into difficulties, and perhaps this arrangement should always be considered by race organisers.

The low injury rates endured by the three and a half thousand runners in the Sheffield Marathon means that in the general care, participating in such events, and the events themselves, should not be a cause for concern medically.

\section{ACKNOWLEDGEMENTS}

We thank the British Red Cross Society South Yorkshire Branch, the Organising Committee of the Sheffield Marathon, and Mr. John Whetton, race director, for the facilities to undertake this study.

The action photographs were provided by courtesy of Mike Ford, Photographer, 10 Carver Street, Sheffield 1.

\section{REFERENCES}

Maughan, R. J. and Miller, J. D. B., 1982 "Popular marathons: forecasting the casualties". British Medical Journal 285: 1736 (correspondence).

Nicholl, J. P. and Williams, B. T., 1982a. "Popular marathons: forecasting the casualties". British Medical Journal 285: 1464-5.

Nicholl, J. P. and Williams, B. T., 1982b. "Medical problems before and after a popular marathon". British Medical Journal 285: 1465-6.

Running Magazine, June 1982, p. 21, London, BEL Ltd. 